\title{
Effects of IL-13 on Mucociliary Differentiation of Pediatric Asthmatic Bronchial Epithelial Cells
}

\author{
SURENDRAN THAVAGNANAM, JEREMY C. PARKER, MICHAEL E. MCBRIEN, GRZEGORZ SKIBINSKI, LIAM G. HEANEY, \\ AND MICHAEL D. SHIELDS \\ Centre for Infection and Immunity [S.T., J.C.P., G.S., L.G.H., M.D.S.], Queen's University Belfast, Belfast BT12 6BN, Northern Ireland, \\ United Kingdom; Department of Anaesthetics [M.E.M.], Royal Victoria Hospital, Belfast BT12 6BE, Northern Ireland, United Kingdom; \\ Department of Pediatrics [M.D.S.], Royal Belfast Hospital for Sick Children, Belfast BT12 6BE, Northern Ireland, United Kingdom
}

\begin{abstract}
Goblet cell hyperplasia $(\mathrm{GCH})$ and decreased ciliated cells are characteristic of asthma. We examined the effects of IL-13 (2 and $20 \mathrm{ng} / \mathrm{mL}$ ) on in vitro mucociliary differentiation in pediatric bronchial epithelial cells (PBECs) of normal PBEC [PBEC(N)] and asthmatic PBEC [PBEC(A)] children. Markers of differentiation, real-time PCR for MUC5AC, MUC5AC ELISA, and transepithelial electrical resistance (TEER) were assessed. Stimulation with 20 $\mathrm{ng} / \mathrm{mL}$ IL-13 in PBEC(N) resulted in GCH $[20 \mathrm{ng} / \mathrm{mL}$ IL-13: mean, $33.8 \%$ (SD, 7.2) versus unstimulated: mean, $18.9 \%$ (SD, 5.0); $p<$ $0.0001]$ and decreased ciliated cell number [20 ng/mL IL-13: mean, $8 \%$ (SD, 5.6) versus unstimulated: mean, $22.7 \%$ (SD,7.6); $p<0.01]$. PBEC(N) stimulated with $20 \mathrm{ng} / \mathrm{mL}$ IL-13 resulted in $>5$-fold (SD, 3.2) increase in MUC5AC mRNA expression, $p<0.001$, compared with unstimulated PBEC(N). In PBEC(A), GCH was also seen [20 ng/mL IL-13: mean, $44.7 \%$ (SD, 16.4) versus unstimulated: mean, $30.4 \%$ (SD, 13.9); $p<0.05]$ with a decreased ciliated cell number [20 ng/mL IL-13: mean, 8.8\% (SD, 7.5) versus unstimulated: mean, $16.3 \%$ (SD, 4.2); $p<0.001]$. We also observed an increase in MUC5AC mRNA expression with $20 \mathrm{ng} / \mathrm{mL}$ IL-13 in PBEC(A), $p<$ 0.05 . IL-13 drives $\operatorname{PBEC}(\mathrm{N})$ toward an asthmatic phenotype and worsens the phenotype in PBEC(A) with reduced ciliated cell numbers and increased goblet cells. (Pediatr Res 69: 95-100, 2011)
\end{abstract}

A number of studies have demonstrated that $\mathrm{T}$ helper 2 cells (Th-2) cytokines play a critical role in allergic asthma and that IL-13 is a central mediator in the regulation of this allergic diathesis (1-4). In asthma, goblet cell hyperplasia $(\mathrm{GCH})$ is a major contributing factor to the disease, resulting in excessive mucus production (5) and mucus plugging in the airway lumen (6). This is one of the likely pathways involved

Received May 10, 2010; accepted September 26, 2010.

Correspondence: Michael D. Shields, M.D., Centre for Infection and Immunity, Microbiology Building, Queen's University Belfast, Grosvenor Road, Belfast BT12 6BN, Northern Ireland, United Kingdom; e-mail: m.shields@qub.ac.uk

Supported by the Irish Thoracic Society-Boehringer Ingelheim Research Fellowship, Northern Ireland Chest, Heart and Stroke Association, and the James Trust, British Medical Association.

Presented, in part, at the Annual meeting of the British Thoracic Society 2008 and European Respiratory Society 2009.

L.G.H. and M.D.S. are joint senior authors

Supplemental digital content is available for this article. Direct URL citations appear in the printed text and are provided in the HTML and PDF versions of this article on the journal's Web site (www.pedresearch.org). in an increased frequency and duration of infection, decline in lung function, and increased morbidity and mortality (7).

The exact role of IL-13 in pediatric asthma has not been studied widely. Animal studies have confirmed an essential role for IL-13 in driving GCH and other correlates of asthma pathology, including airway hyperresponsiveness, lung eosinophilia, and subepithelial fibrosis and thickened smooth muscle $(8-12)$. Previous studies suggest that airway epithelial cells are direct targets for IL-13 $(12,13)$; however, the use of epithelial cell lines in these studies could not really address the question of how IL-13 could contribute to airway remodeling. It has also been suggested that IL-13 could cause epithelial barrier dysfunction, and more recently, interest has increased in relation to the effects of IL-13 on tight junction formation (14). It is currently unknown as to whether IL-13 impairs epithelial "tight junction" formation during the altered differentiation process of bronchial epithelial cells. In addition, there are no data available looking at the effects of IL-13 on pediatric bronchial epithelial cells (PBECs) and whether it influences the epithelial differentiation process in a similar manner to adults.

Investigating the airway epithelium during childhood is important because many of the questions surrounding the initial pathophysiological mechanisms in asthma and the evolution of airways remodeling can be addressed at this stage (15). This is also the time when interventions are more likely to alter the natural history of the disease.

We have established a 3D well-differentiated model of PBECs, which, we believe, mimics the bronchial epithelium in vivo (16). Under basal unstimulated conditions, we have previously demonstrated that cultures from asthmatic PBEC, PBEC(A), children contained significantly more goblet cells and fewer ciliated cells compared with those from normal PBEC, PBEC(N), children (16).

\footnotetext{
Abbreviations: ALI, air liquid interface; GCH, goblet cell hyperplasia; PBEC, pediatric bronchial epithelial cells; PBEC(A), asthmatic pediatric bronchial epithelial cells; $\operatorname{PBEC(N)}$, normal pediatric bronchial epithelial cells; TEER, transepithelial electrical resistance
} 
Our hypothesis in this study was that chronic exposure of PBECs to IL-13 during mucociliary differentiation would result in GCH and a reduction in the number of ciliated cells in both PBEC(A) and PBEC(N). In addition, we hypothesized that IL-13 could be the driving factor behind the morphological changes seen in our previously observed unstimulated asthmatic phenotype (16). We were particularly interested in determining whether $\operatorname{PBEC}(\mathrm{N})$ could be "transitioned" to an asthmatic type phenotype after IL-13 stimulation and whether IL-13 stimulation affected transepithelial electrical resistance (TEER) as a measure of epithelial tight junction formation.

\section{METHODS}

Children younger than $12 \mathrm{y}$ [mean age, $8.2 \mathrm{y}$ (range, 2-12 y)] attending elective surgical procedures at the Royal Belfast Hospital for Sick Children were recruited. A doctor administered semistructured proforma was used to record the clinical history (online supplemental data available at http://links.lww.com/PDR/A64) (17), and children were classified into two groups: asthmatic (recurrent wheezing within the last year) and normal (controls) who had never wheezed. All asthmatic children were on a regular inhaled corticosteroid and rescue short-acting beta-agonist therapy as required for symptoms, whereas the normal children were not on any treatment. Written informed parental consent and where appropriate child assent was obtained. This study was approved by the Office of the Research Ethics Committees of Northern Ireland (ORECNI).

Isolation of primary PBECs. Nonbronchoscopic bronchial brushings were obtained from asthmatic children $(n=10)$ and normal children $(n=10)$ as previously described (18). Briefly, the cells obtained from the bronchial brushes were removed and centrifuged. The pellet was then seeded into one collagen-coated T10 flask until they were $80 \%$ confluent before transferring them to a collagen-coated T75 flask and finally onto collagen-coated transwells at $0.8 \times 10^{5}$ seeding density. PBECs were cultured using methods developed in our laboratory, which resulted in homogenous cultures of basal epithelial cells (16). Bronchial brush washings were analyzed for viruses using a multiviral PCR analysis, and only uncontaminated cultures were used.

Air liquid interface cultures for establishment of well-differentiated mucociliary epithelium. Air liquid interface (ALI) cultures were grown as previously described (16). All cells from subjects used in this study were grown at ALI at passage 3. The cells were grown in transwells submerged for the first 9-14 d, during which time the culture medium was changed on $\mathrm{d} 1$ and every other day thereafter. Once the cells reach $100 \%$ confluence, ALI was created by removing the apical medium and restricting the culture feeding to the basolateral compartment. After ALI creation, the culture medium was changed on alternate days, and the cells were then differentiated at ALI for $28 \mathrm{~d}$ to ensure full differentiation as assessed by the presence of beating cilia and mucus on the apical surface of the cultures.

Stimulation of PBECS with IL-13. After establishment of ALI, cells were fed basolaterally every other day with ALI medium supplemented with recombinant human IL-13 (PeptroTech EC, Ltd., London, United Kingdom) at two different concentrations ( 2 and $20 \mathrm{ng} / \mathrm{mL}$ ) in line with previous studies, which have used concentrations ranging from 0.1 to $100 \mathrm{ng} / \mathrm{mL}$ to demonstrate any potential dose response (19-24). The apical side was washed weekly with $\mathrm{PBS}$ at $37^{\circ} \mathrm{C}$.

TEER. We used TEER as a measure of "tight junction" formation in epithelial cultures (25). TEER was measured on d 7, 14, 21, and 28 of ALI culture using an EVOM meter (World Precision Instruments, FL) as previously described (16). The TEER of six inserts per treatment group was measured at each time point, and the average was calculated. Briefly, the apical surface was washed before reading with warm PBS $(500 \mu \mathrm{L})$. After aspiration, warm DMEM with no additives was applied apically followed by the TEER being measured. The DMEM was then removed, and the cultures were fed as per normal. PBS washings were stored for further analysis.

Immunocytochemistry (ICC) for goblet and ciliated cell markers. Cytospin slides were made to allow for the detection of MUC5AC-positive (goblet) and acetylated alpha-tubulin-positive (ciliated) cells from the PBEC cultures as previously described (16). Immediately after trypsinization of the PBECs, cytospin slides were prepared with a cell density of $5.0 \times 10^{4}$ cells per slide. Immunostaining was performed using anti-MUC5AC antibody (1:100; Abcam, Cambridge, United Kingdom) and acetylated alpha tubulin (1:700; Abcam) for goblet and ciliated cells, respectively. The reaction between the antigen and the antibody was detected using a perixodaseconjugated anti-mouse secondary antibody. Negative controls were subjected to routine conditions with the omission of the primary antibody. MUC5AC and acetylated alpha tubulin positive cells were counted at a magnification of $\times 60$ blindly in six fields of vision and are expressed as the $\%$ of the total cells counted per slide (500 cells/slide). The result of the mean $\%$ of goblet cells and ciliated cells from the three slides per stain per insert is expressed in this article.

Confocal microscopy. For confocal microscopy, cells were permeabilized using $0.2 \%$ Triton X-100 (Sigma Chemical Co.-Aldrich, Dorset, United Kingdom) for $1 \mathrm{~h}$ at $37^{\circ} \mathrm{C}$ followed by three washes in PBS. Cells were then exposed to either a 1:100 dilution of rabbit anti-MUC5AC primary antibody (goblet cells; Santa Cruz Biotechnology, Inc., CA) or a 1:100 dilution of mouse MAb against acetylated alpha tubulin (ciliated cells; Abcam) overnight at $4^{\circ} \mathrm{C}$. After washing, cells were exposed to a 1:250 dilution of Alexaflour 561 goat-anti mouse IgG (Invitrogen, Ltd., Paisley, United Kingdom) and a 1:100 dilution of goat anti-rabbit IgG FITC (Invitrogen, Ltd.) at $4{ }^{\circ} \mathrm{C}$ in the dark for $1 \mathrm{~h}$. After a gentle wash with PBS, the membrane was cut out from the insert using a scalpel and then mounted on a slide using Vectashield with 4',6-diamidino-2-phenylindole (DAPI; Vector Laboratories, Peterborough, United Kingdom). Fluorescent images were viewed on a Leica SP5 confocal DMI 6000 inverted microscope equipped with a krypton-argon laser as the source for the ion beam using a $\times 40$ oil immersion (numerical aperture, 1.25). Images were captured and viewed using LAS AF (Leica) acquisition software. Negative controls (omission of primary antibody) were used to test the specificity of the antibodies and the staining protocol.

RNA extraction and real-time PCR for MUC5AC mRNA. Total RNA was isolated from lysates of PBECs using the RNeasy Mini kit (Qiagen, Crawley, United Kingdom) according to the manufacturer's instructions and quantified on a spectrophotometer. One microgram of RNA from each sample was reverse transcribed in a $20-\mu \mathrm{L}$ reaction using First Strand cDNA synthesis kit (AMV-Roche) according to recommended conditions. For the PCR reaction, the DNA amplification was carried out using the Fast Start Universal SYBR Green Master (Rox; Roche, United Kingdom). For each PCR reaction, separate PCR Master Mixes were prepared containing GAPDH (Tebu-bio, Peterbrough, United Kingdom), MUC5AC, or IL-13 (R\&D Systems, Abingdon, United Kingdom) primers. RT-PCR was performed on the ABI Prism 7000 (Applied Biosystems, United Kingdom) sequence detection system using GAPDH as the internal control. An identical threshold cycle $(\mathrm{Ct})$ was applied for each gene of interest. Relative mRNA expression levels were calculated using the delta Ct method. MUC5AC primers (Invitrogen, Ltd.) were designed according to the following description:

Forward 5' TCC TTT CGT GTT GTC ACC GA 3' localization on cDNA: $2874 \mathrm{bp}$.

Reverse 5' TCT TGA TGG CCT TGG AGC 3' localization on cDNA: 2943 bp.

MUC5AC ELISA. Production of MUC5AC protein in the apical washes from PBECs was measured using an in-house MUC5AC ELISA. As no MUC5AC standard was commercially available, this ELISA produced a semi-quantitative analysis of the production of this protein by comparing cultures treated with IL-13 compared with unstimulated cultures. A 96-well high-binding ELISA plate (Corning Costar) was coated with experimental samples at $40^{\circ} \mathrm{C}$ overnight. The plate was then washed three times with PBS. Wells were blocked with a solution of $2 \%$ BSA in PBS for $1 \mathrm{~h}$ at room temperature. After three washes with PBS, samples were exposed to primary antibody diluted to 1:200 in PBS containing 0.05\% Tween20 (Sigma Chemical Co-Aldrich). After incubating for $1 \mathrm{~h}$, the plate was washed three times and labeled with an horseradish peroxidase (HRP)-conjugated goat antimouse $\operatorname{IgG}$ (Jackson Laboratories) diluted to $1: 10,000$ in PBS $+0.05 \%$ Tween 20 and incubated for $1 \mathrm{~h}$. After the secondary antibody incubation, the plate was washed with PBS, and the color reaction was developed with 100 $\mu \mathrm{L}$ of TMB (Millipore, United Kingdom) per well incubated for $15 \mathrm{~min}$ at room temperature in the dark. $\mathrm{A} 1 \mathrm{M} \mathrm{H}_{2} \mathrm{SO}_{4}$ solution was then added to halt color development, and absorbance was read at $450 \mathrm{~nm}$.

IL-13 ELISA. We performed an IL-13 ELISA using supernatants from unstimulated cultures to determine whether the PBECs were producing and secreting IL-13. Apical washings and basolateral aliquots taken on d 7, 14, 21, and 28 of ALI culture were analyzed for IL-13 secretion using an ELISA kit (Pierce Biotechnology) as per manufacturer's instructions.

Statistical analysis. We expressed results as mean (SD), and skewed variables were log transformed before making statistical comparisons. Comparisons between groups (asthma versus normal) were made using one- and two-way repeated measures ANOVA. The repeated values within individual patients was time (d 7, 14, 21, and 28) for TEER values and IL-13 protein production using ELISA testing and the three concentrations of IL-13 (control, 2 and $20 \mathrm{ng} / \mathrm{mL}$ IL-13) for immumocytochemistry counts. We tested to see if the clinical group (asthma versus normal) and stimulation concentration 
(control, 2 and $20 \mathrm{ng} / \mathrm{mL}$ IL-13) interactions were statistically significant indicating that $\operatorname{PBEC}(\mathrm{A})$ responded differently to $\operatorname{PBEC}(\mathrm{N})$ to increasing stimulation concentration of IL13. We tested for the simple factor effects (clinical group and stimulation concentration) and used Bonferroni corrections for post hoc tests. Analysis of fold change in MUC5AC mRNA expression and MUC5AC relative absorbance were made against unstimulated cultures in $\operatorname{PBEC}(\mathrm{N})$ and $\operatorname{PBEC}(\mathrm{A})$. We used the $t$ test to compare the unstimulated normal versus asthmatic immunocytochemistry values. A $p<$ 0.05 was taken as statistically significant.

\section{RESULTS}

Effects of IL-13 on PBEC(A) and PBEC(N). Both $\operatorname{PBEC}(\mathrm{A})$ and PBEC(N) formed a pseudostratified columnar epithelium. The TEER at each time point measured was between 200 and 800 [Omega] $\mathrm{cm}^{2}$ confirming "tight junction" formation (25). In $\operatorname{PBEC}(\mathrm{N})$ and $\operatorname{PBEC}(\mathrm{A})$, we detected no overall differences or changes in TEER values over time or with IL-13 stimulation (Fig. $1 A$ and $B$ ).

The \% goblet cells were lower in PBEC(N) compared with $\operatorname{PBEC}(\mathrm{A})$ under unstimulated conditions [PBEC $(\mathrm{N})$ : mean, $18.9 \%$ (SD, 5) versus PBEC(A): mean, 30.4\% (SD, 13.9); $p<$ $0.05]$. The $\%$ goblet cells increased in both $\operatorname{PBEC}(\mathrm{N})$ and PBEC(A) with increasing IL-13 stimulation concentration ( $p<0.05$; Fig. 2A). Interestingly, $\operatorname{PBEC}(\mathrm{N})$ when stimulated with $20 \mathrm{ng} / \mathrm{mL}$ IL-13, resulted in a similar \% of goblet cells when compared with unstimulated $\operatorname{PBEC}(\mathrm{A})$ [PBEC $(\mathrm{N})$ treated with $20 \mathrm{ng} / \mathrm{mL}$ IL-13: mean, 33.8\% (SD, 7.2) versus unstimulated PBEC(A): mean, 30.4\% (SD, 13.9)]. The \% goblet cells for PBEC(A) stimulated with $20 \mathrm{ng} / \mathrm{mL}$ IL-13 were higher than PBEC(N) after stimulation [PBEC(N): mean, 33.8\% (SD, 7.2) versus $\mathrm{PBEC}(\mathrm{A})$ : mean, 44.7\% (SD, 16.4); $p<0.05$ ].

The $\%$ ciliated cells were higher in $\operatorname{PBEC}(\mathrm{N})$ compared with $\mathrm{PBEC}(\mathrm{A})$ under unstimulated conditions $[\mathrm{PBEC}(\mathrm{N})$ :

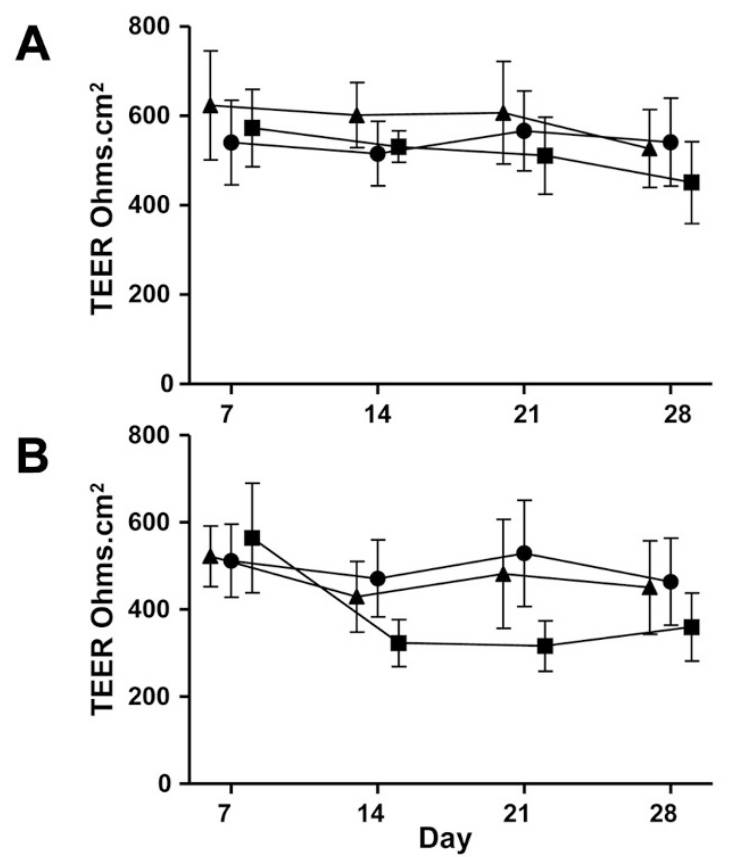

Figure 1. TEER of $\operatorname{PBEC}(\mathrm{N})(A)$ and $\operatorname{PBEC}(\mathrm{A})(B)$ cultures for $28 \mathrm{~d}$ and treated with 2 or $20 \mathrm{ng} / \mathrm{mL}$ IL-13. Values expressed as mean \pm SEM. There was no significant difference seen in the TEER between the treatment groups in both $\operatorname{PBEC}(\mathrm{N})$ and $\operatorname{PBEC}(\mathrm{A}) . \boldsymbol{\bullet}$, control; $\boldsymbol{\Lambda}, 2 \mathrm{ng} / \mathrm{mL}$ IL-13; and $\mathbf{\square}, 20$ $\mathrm{ng} / \mathrm{mL}$ IL-13.
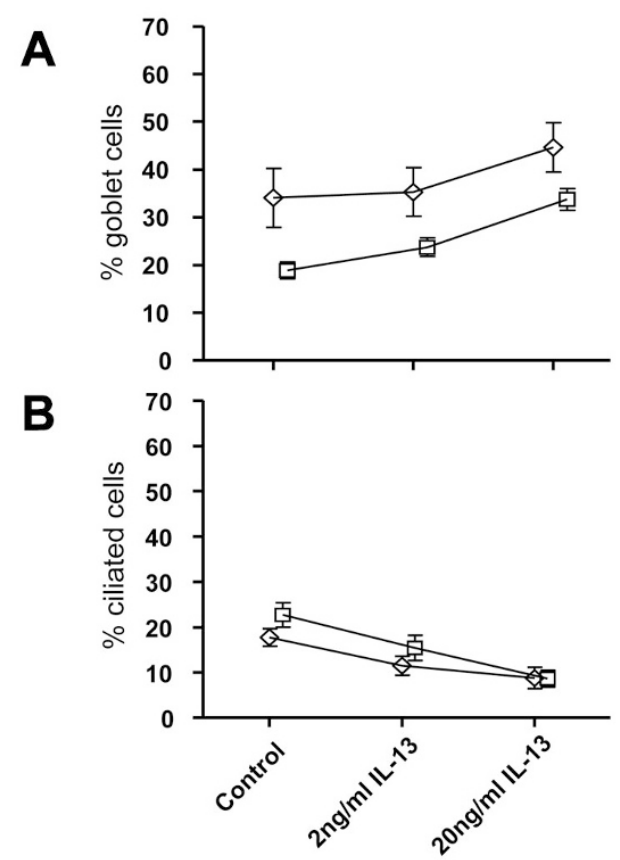

Figure 2. The $\%$ of goblet $(A)$ and ciliated $(B)$ cells of $\operatorname{PBEC}(\mathrm{N})(\square)$ and PBEC(A) $(\diamond)$ treated with 2 and $20 \mathrm{ng} / \mathrm{mL}$ IL-13 on d 28 of ALI culture. Values are expressed as mean \pm SEM. The $\%$ goblet cells is increased $(p<$ $0.05)$, and $\%$ ciliated cells is decreased $(p<0.001)$ in both $\operatorname{PBEC}(\mathrm{N})$ and PBEC(A) with increasing IL-13 stimulation concentration (Fig. $2 A$ and $B$, respectively).

mean, 22.7\% (SD, 7.6) versus $\mathrm{PBEC}(\mathrm{A})$ : mean, 16.3\% (SD, $4.2) ; p<0.05$; Fig. $2 B$ ]. The $\%$ ciliated cells decreased in both $\operatorname{PBEC}(\mathrm{N})$ and $\operatorname{PBEC}(\mathrm{A})$ with increased IL-13 stimulation concentration $[p<0.001$; PBEC(N) with $20 \mathrm{ng} / \mathrm{mL}$ IL-13 reduced from mean, $22.7 \%(\mathrm{SD}, 7.6)$ to mean, $8 \%$ (SD, 5.6) and $\mathrm{PBEC}(\mathrm{A})$ with $20 \mathrm{ng} / \mathrm{mL}$ IL-13 reduced from mean, 16.3 (SD, 4.2) to $8.8 \%$ (SD, 7.5; Fig. 2B)].

We confirmed this goblet cell hyperplasia and decreased presence of ciliated cells in $\operatorname{PBEC}(\mathrm{N})$ (Fig. 3A-D) and

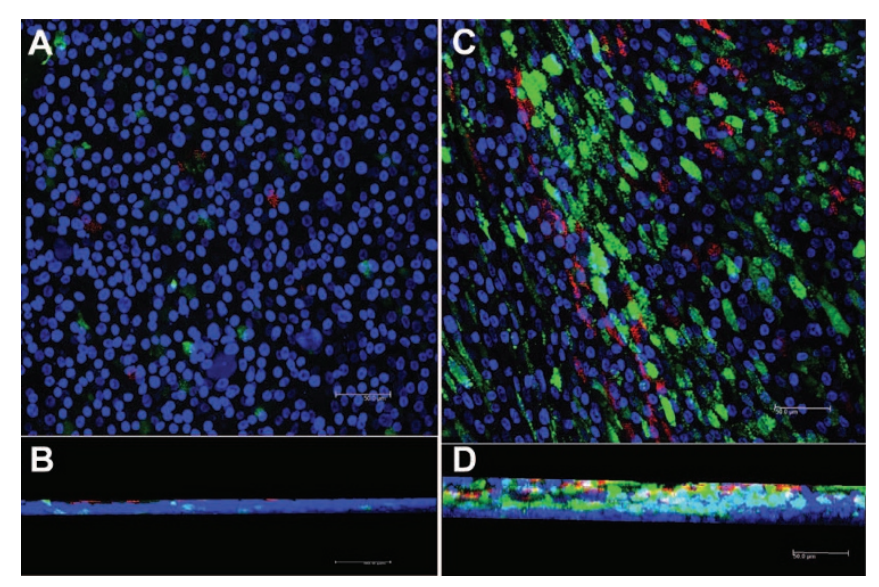

Figure 3. Immunofluorescence and confocal microscopy of $\operatorname{PBEC}(\mathrm{N})$ at $d$ 28 culture of ALI. Goblet cells indicated by green staining, ciliated cells indicated by red staining, and nuclei stained blue with DAPI $(\times 40)$. Representative image of $(A)$ apical surface and $(B)$ z-stack of an unstimulated $\operatorname{PBEC}(\mathrm{N})$ and $(C)$ apical surface and $(D)$ z-stack of a PBEC $(\mathrm{N})$ treated with $20 \mathrm{ng} / \mathrm{mL}$ IL-13. Images $(C)$ and $(D)$ show an increased presence of goblet cells and decreased presence of ciliated cells after stimulation with $20 \mathrm{ng} / \mathrm{mL}$ IL-13 compared with unstimulated $\operatorname{PBEC}(\mathrm{N})$. 

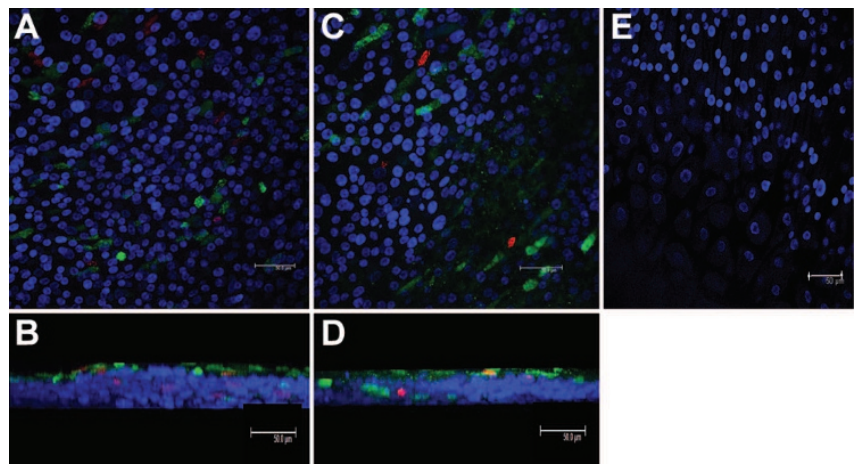

$\mathbf{B}$

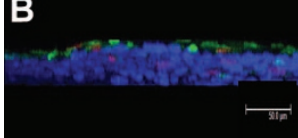

D

Figure 4. Immunofluorescence and confocal microscopy of PBEC(A) at $d$ 28 culture of ALI. Goblet cell indicated by green staining, ciliated cell indicated by red staining, and nuclei stained blue with DAPI $(\times 40)$. Representative image of $(A)$ apical surface and $(B)$ z-stack of an unstimulated PBEC(A) and $(C)$ apical surface and $(D)$ z-stack of PBEC(A) treated with 20 $\mathrm{ng} / \mathrm{mL}$ IL-13. Images $(C)$ and $(D)$ show an increased presence of goblet cells and decreased presence of ciliated cells after stimulation with $20 \mathrm{ng} / \mathrm{mL} \mathrm{IL-13}$ compared with unstimulated $\operatorname{PBEC}(\mathrm{A})$. Image $(E)$ is the negative control of PBEC(A) without the primary antibody.

PBEC(A) (Fig. 4A-D) using immunofluorescent staining and confocal microscopy.

We found MUC5AC mRNA expression increased for both $\operatorname{PBEC}(\mathrm{N})$ and $\operatorname{PBEC}(\mathrm{A})$ with the increasing concentration of IL-13 [ $p<0.001$; PBEC(N) with $20 \mathrm{ng} / \mathrm{mL}$ IL-13 mean fold increase 5 (SD, 3.2) versus unstimulated and PBEC(A) with $20 \mathrm{ng} / \mathrm{mL}$ IL-13 mean fold increase 9.4 (SD, 11.2) versus unstimulated; Fig. 5].

In PBEC(N), in parallel with the increased MUC5AC mRNA expression, the relative absorbance of MUC5AC in culture supernatants was increased in response to IL-13 stimulation $[p<0.001 ; 20 \mathrm{ng} / \mathrm{mL}$ IL-13: mean, 3.0 (SD, 0.5); 2 ng/mL IL-13: mean, 2.8 (SD, 0.6) versus unstimulated: mean, 1.9 (SD, 0.7; Fig. 6)]. However, in PBEC(A), despite increased MUC5AC mRNA expression, there was no significant increase in relative absorbance of MUC5AC [20 ng/mL IL-13: mean, 2.4 (SD, 0.9) and $2 \mathrm{ng} / \mathrm{mL}$ IL-13: mean, 2.6 (SD, 0.8) versus unstimulated: mean, 2.5 (SD, 0.6; Fig. 6)]. We found

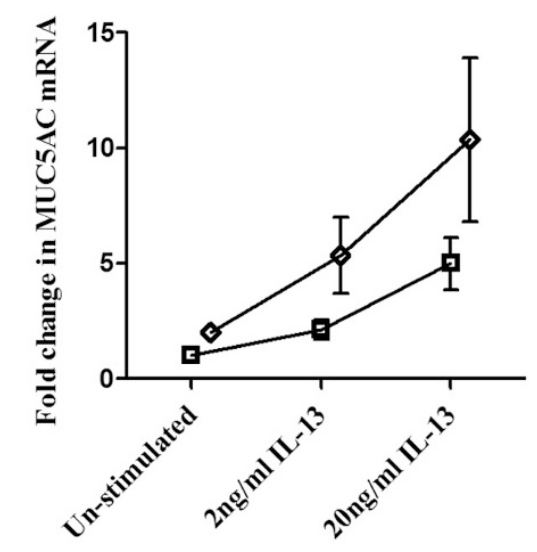

Figure 5. Fold increase in expression of MUC5AC mRNA from PBEC(N) $(\square)$ and PBEC(A) $(\diamond)$ treated with IL-13 measured on d 28 of ALI culture using real-time PCR. Values are expressed as mean \pm SEM. There is significant fold increase in MUC5AC mRNA expression in both PBEC(N) and PBEC(A), $p<0.001$.

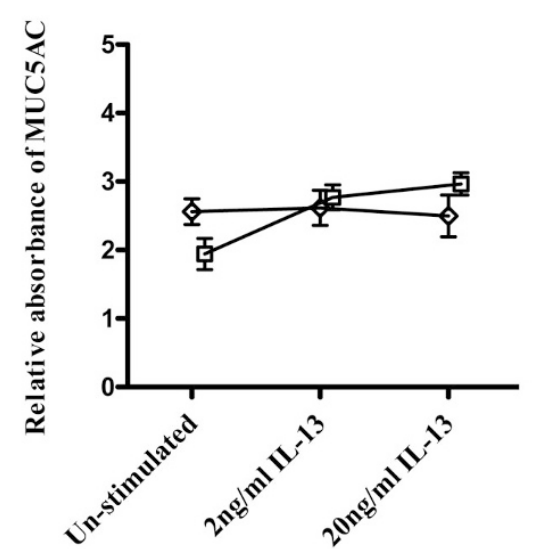

Figure 6. Relative absorbance of MUC5AC of PBEC(N) ( $\square$ ) and PBEC(A) $(\diamond)$ treated with IL-13 measured on d 28 of ALI culture using ELISA. Values are expressed as mean \pm SEM. The relative absorbance of MUC5AC was increased in $\operatorname{PBEC}(\mathrm{N})$ response to IL-13 stimulation, $p<0.001$ only.

that only a weak to moderate correlation existed between numbers of goblet cells, MUC5AC mRNA, and MUC5AC protein measured by ELISA (data not shown).

Previous studies have suggested that epithelial cells are capable of producing IL-13 under unstimulated and wound repair conditions (26); however, we could not detect IL-13 (mRNA or protein) in either the apical or basolateral washes from both cultures (normal and asthmatic) under unstimulated conditions.

\section{DISCUSSION}

In our previous studies, we found that PBEC(A) exhibited a significant GCH and decreased ciliogenesis compared with PBEC(N) under unstimulated conditions (16). It is commonly known that IL-13 is a key cytokine in the pathogenesis of asthma and has been attributed with driving the aforementioned effects in normal airway epithelium, and therefore, our original hypothesis for this study was that IL-13 would not only be responsible for driving $\operatorname{PBEC}(\mathrm{N})$ epithelium to that of an asthmatic phenotype but also drive PBEC(A) toward a more adverse asthmatic phenotype.

IL-13 has been shown to cause disruption of the epithelial barrier in in vitro models (14). However, we did not observe any effect of IL-13 in TEER in either PBEC(A) or PBEC(N), suggesting a lack of effect of IL-13 in the integrity of "tight junctions" in asthmatic and normal epithelium. A limitation of our study of tight junction formation is that we did not perform additional measures of "tight junction" integrity for example using FITC dextran to measure permeability or assessing specific tight junction complexes such as claudins.

We have shown that IL-13 stimulation of $\operatorname{PBEC}(\mathrm{N})$ produced a dose-dependent increase in the number of goblet cells. At the stimulatory concentration of $20 \mathrm{ng} / \mathrm{mL}$ IL-13, the $\%$ of goblet cells was indeed similar to that of PBEC(A) under unstimulated conditions, thereby supporting our hypothesis that IL-13 is the cause of driving a GCH in normal epithelium, leading eventually to the airway remodeling associated with asthmatic epithelium (19). Our results also confirm that in $\operatorname{PBEC}(\mathrm{N})$, IL-13 resulted in a significant increase in 
MUC5AC mRNA production with a subsequent and significant effect on MUC5AC protein expression from goblet cells as seen in our ELISA analysis $(1,21,27)$. A number of different stimuli have been shown to regulate MUC5AC expression and cause an increase in the number of mucus-producing goblet cells but this study as with others suggests that IL-13 is the main cytokine implicated (28-30). We also observed a significant decrease in the number of ciliated cells in cultures treated with $20 \mathrm{ng} / \mathrm{mL} \mathrm{IL-13,} \mathrm{again} \mathrm{agreeing} \mathrm{with} \mathrm{previous}$ findings that in normal epithelium IL-13 can drive this anticiliogenic effect.

This anticiliogenic effect was also seen in asthmatic cultures treated with $20 \mathrm{ng} / \mathrm{mL}$ IL-13, showing a significant reduction in the number of ciliated cells which may, in part, explain why asthmatic patients have abnormal mucociliary clearance resulting in the buildup of mucus in the airway lumen. However, an important additional finding from this study is that IL-13 stimulation seems to be able to further enhance $\mathrm{GCH}$ in bronchial epithelium from asthmatic children. Our findings have also highlighted that although the unstimulated bronchial epithelial cells from normal and asthmatic children differ morphologically, they respond to IL-13 stimulation in a similar manner. This finding further highlights IL-13 as a key therapeutic target in asthma.

We observed that under unstimulated conditions, $\operatorname{PBEC}(\mathrm{A})$ already expressed higher quantities of MUC5AC mRNA and already had significantly more goblet cells compared with PBEC(N) (16). This led us to assess whether IL-13 is in fact the driver behind unstimulated GCH in asthmatic epithelium. In an earlier study, Allahverdian et al. (26) suggested that SV40-transformed normal adult human airway epithelial cells could produce $20 \mathrm{ng} / \mathrm{mL}$ IL-13 under unstimulated conditions, with this level rising when the epithelium is wounded. If this finding was indeed the case, we postulated that this may be a causative factor in the GCH and decreased ciliogenesis seen in our unstimulated asthmatic epithelium. To test this, we analyzed our unstimulated asthmatic cultures using real-time PCR and ELISA for IL-13 mRNA production and protein secretion. We found our cultures to produce no detectable quantities of IL-13 either at the level of message or protein, leading us to conclude that IL-13 is not the main cause of the asthmatic phenotype seen in our unstimulated cultures. This would suggest that it is via an IL-13 independent effect that our asthmatic cultures are differentiating to this phenotype, which we are currently investigating. The origins of goblet cells are not well understood, although Clara cells (31) and ciliated cells $(20,32)$ have been implicated as goblet cell progenitors, which might explain the increase in goblet cell numbers in our asthmatic cultures. We cannot completely exclude that the difference in unstimulated asthmatic cultures is because of a "carry-over effect" from IL-13 in vivo. However, given the duration of culture, we believe this is unlikely and suggests that an alternative IL13-independent mechanism, such as the EGF pathway, or an inherent mechanism for GCH in asthma may be present, which we are currently exploring in our laboratory.
In conclusion, in vitro stimulation with IL-13 drives $\operatorname{PBEC}(\mathrm{N})$ toward an asthmatic phenotype and worsens the asthmatic phenotype in PBEC(A) with a significant GCH and decrease in ciliated cell number and no obvious effect on tight junction integrity. In addition, IL-13 seemed not to be the causative factor in driving $\mathrm{GCH}$ and ciliated cell effects in our unstimulated asthmatic epithelium, suggesting a potential IL-13 independent or inherent mechanism. A further understanding of the origin and processes regulating goblet cell formation in human airway epithelial cells needs to be investigated further as they have important implications for identification of therapeutic targets to treat respiratory disease.

Acknowledgments. We thank Mr. English, Ear Nose and Throat Surgeon, for allowing us to recruit his patients for this study.

\section{REFERENCES}

1. Grünig G, Warnock M, Wakil AE, Venkayya R, Brombacher F, Rennick DM Sheppard D, Mohrs M, Donaldson DD, Locksley RM, Corry DB 1998 Requirement for IL-13 independently of IL-4 in experimental asthma. Science 282:2261-2263

2. Wills-Karp M, Luyimbazi J, Xu X, Schofield B, Neben TY, Karp CL, Donaldson DD 1998 Interleukin-13: central mediator of allergic asthma. Science 282:22582261

3. Wills-Karp M, Chiaramonte M 2003 Interleukin-13 in asthma. Curr Opin Pulm Med 9:21-27

4. Zheng T, Zhu Z, Wang Z, Homer RJ, Ma B, Riese RJ, Chapman HA Jr, Shapiro SE, Elias JA 2000 Inducible targeting of IL-13 to the adult lung causes matrix metalloproteinase- and cathepsin-dependent emphysema. J Clin Invest 106:1081-1093

5. Aikawa T, Shimura S, Sasaki H, Ebina M, Takishima T 1992 Marked goblet cell hyperplasia with mucus accumulation in the airways of patients who died of severe acute asthma attack. Chest 101:916-921

6. Kuyper LM, Pare PD, Hogg JC, Lambert RK, Ionescu D, Woods R, Bai TR 2003 Characterization of airway plugging in fatal asthma. Am J Med 115:6-11

7. Vestbo J 2002 Epidemiological studies in mucus hypersecretion. Novartis Found Symp 248:3-12

8. Kibe A, Inoue H, Fukuyama S, Machida K, Matsumoto K, Koto H, Ikegami T, Aizawa H, Hara N 2003 Differential regulation by glucocorticoid of interleukin-13induced eosinophilia, hyperresponsiveness, and goblet cell hyperplasia in mouse airways. Am J Respir Crit Care Med 167:50-56

9. Fulkerson PC, Fischetti CA, Hassman LM, Nikolaidis NM, Rothenberg ME 2006 Persistent effects induced by IL-13 in the lung. Am J Respir Cell Mol Biol 35:337-346

10. Naseer T, Minshall EM, Leung DY, Laberge S, Ernst P, Martin RJ, Hamid Q 1997 Expression of IL-12 and IL-13 mRNA in asthma and their modulation in response to steroid therapy. Am J Respir Crit Care Med 155:845-851

11. Humbert M, Durham SR, Kimmitt P, Powell N, Assoufi B, Pfister R, Menz G, Kay AB, Corrigan CJ 1997 Elevated expression of messenger ribonucleic acid encoding IL-13 in the bronchial mucosa of atopic and nonatopic subjects with asthma. J Allergy Clin Immunol 99:657-665

12. Matsukura S, Stellato C, Georas SN, Casolaro V, Plitt JR, Miura K, Kurosawa S, Schindler U, Schleimer RP 2001 Interleukin-13 upregulates eotaxin expression in airway epithelial cells by a STAT6-dependent mechanism. Am J Respir Cell Mol Biol 24:755-761

13. Propst SM, Denson R, Rothstein E, Estell K, Schwiebert LM 2000 Proinflammatory and Th2-derived cytokines modulate CD40-mediated expression of inflammatory mediators in airway epithelia: implications for the role of epithelial CD40 in airway inflammation. J Immunol 165:2214-2221

14. Ahdieh M, Vandenbos T, Youakim A 2001 Lung epithelial barrier function and wound healing are decreased by IL- 4 and IL-13 and enhanced by IFN-gamma. Am J Physiol Cell Physiol 281:C2029-C2038

15. Baena-Cagnani C, Rossi GA, Canonica GW 2007 Airway remodelling in children: when does it start? Curr Opin Allergy Clin Immunol 7:196-200

16. Parker J, Sarlang S, Thavagnanam S, Williamson G, O'Donoghue D, Villenave R, Power U, Shields M, Heaney L, Skibinski G 2010 A 3-D well-differentiated model of pediatric bronchial epithelium demonstrates un-stimulated morphological differences between asthmatic and non-asthmatic cells. Pediatr Res 67:17-22

17. Stevenson EC, Turner G, Heaney LG, Schock BC, Taylor R, Gallagher T, Ennis M, Shields MD 1997 Bronchoalveolar lavage findings suggest two different forms of childhood asthma. Clin Exp Allergy 27:1027-1035

18. Doherty GM, Christie SN, Skibinski G, Puddicombe SM, Warke TJ, de Courcey F, Cross AL, Lyons JD, Ennis M, Shields MD, Heaney LG 2003 Non-bronchoscopic sampling and culture of bronchial epithelial cells in children. Clin Exp Allergy $33: 1221-1225$

19. Atherton HC, Jones G, Danahay H 2003 IL-13-induced changes in the goblet cell density of human bronchial epithelial cell cultures: MAP kinase and phosphatidylinositol 3-kinase regulation. Am J Physiol Lung Cell Mol Physiol 285:L730-L739 
20. Gomperts BN, Kim LJ, Flaherty SA, Hackett BP 2007 IL-13 regulates cilia loss and foxj1 expression in human airway epithelium. Am J Respir Cell Mol Biol 37:339-346

21. Kondo M, Tamaoki J, Takeyama K, Nakata J, Nagai A 2002 Interleukin-13 induces goblet cell differentiation in primary cell culture from Guinea pig tracheal epithelium. Am J Respir Cell Mol Biol 27:536-541

22. Laoukili J, Perret E, Willems T, Minty A, Parthoens E, Houcine O, Coste A, Jorissen M, Marano F, Caput D, Tournier F 2001 IL-13 alters mucociliary differentiation and ciliary beating of human respiratory epithelial cells. J Clin Invest 108:1817-1824

23. Malavia NK, Mih JD, Raub CB, Dinh BT, George SC 2008 IL-13 induces a bronchial epithelial phenotype that is profibrotic. Respir Res 9:27

24. Zhen G, Park SW, Nguyenvu LT, Rodriguez MW, Barbeau R, Paquet AC, Erle DJ 2007 IL-13 and epidermal growth factor receptor have critical but distinct roles in epithelial cell mucin production. Am J Respir Cell Mol Biol 36:244-253

25. Denker BM, Nigam SK 1998 Molecular structure and assembly of the tight junction. Am J Physiol 274:F1-F9

26. Allahverdian S, Harada N, Singhera GK, Knight DA, Dorscheid DR 2008 Secretion of IL-13 by airway epithelial cells enhances epithelial repair via HB-EGF. Am J Respir Cell Mol Biol 38:153-160
27. Zuhdi Alimam M, Piazza FM, Selby DM, Letwin N, Huang L, Rose MC 2000 Muc-5/5ac mucin messenger RNA and protein expression is a marker of goblet cell metaplasia in murine airways. Am J Respir Cell Mol Biol 22:253-260

28. Tanabe T, Fujimoto K, Yasuo M, Tsushima K, Yoshida K, Ise H, Yamaya M 2008 Modulation of mucus production by interleukin-13 receptor alpha2 in the human airway epithelium. Clin Exp Allergy 38:122-134

29. Turner J, Jones CE 2009 Regulation of mucin expression in respiratory diseases Biochem Soc Trans 37:877-881

30. Liu JB, Zhang ZX, Xu YJ, Xing LH, Zhang HL 2004 Effects of interleukin-13 on the gob-5 and MUC5AC expression in lungs of a murine asthmatic model. Zhonghua Jie $\mathrm{He} \mathrm{He} \mathrm{Hu}$ Xi Za Zhi 27:837-840

31. Reader JR, Tepper JS, Schelegle ES, Aldrich MC, Putney LF, Pfeiffer JW, Hyde DM 2003 Pathogenesis of mucous cell metaplasia in a murine asthma model. Am J Pathol 162:2069-2078

32. Tyner JW, Kim EY, Ide K, Pelletier MR, Roswit WT, Morton JD, Battaile JT, Patel AC, Patterson GA, Castro M, Spoor MS, You Y, Brody SL, Holtzman MJ 2006 Blocking airway mucous cell metaplasia by inhibiting EGFR antiapoptosis and IL-13 tranSEMifferentiation signals. J Clin Invest 116:309-321 